\title{
Serum hepcidin in infants born after 32 to 37 wk of gestational age
}

\author{
Lieke Uijterschout ${ }^{1}$, Magnus Domellöf ${ }^{2}$, Staffan K Berglund ${ }^{2}$, Micky Abbink ${ }^{3}$, Paul Vos ${ }^{4}$, Lyanne Rövekamp ${ }^{5}$, Bart Boersma ${ }^{3}$, \\ Carina Lagerqvist ${ }^{2}$, Cisca Hudig ${ }^{6}$, Johannes B van Goudoever ${ }^{7,8}$ and Frank Brus ${ }^{5}$
}

BACKGROUND: Preterm infants are at risk of iron deficiency (ID). Hepcidin has been suggested as a good additional indicator of ID in preterm infants, next to ferritin.

METHODS: In a prospective observational study, we analyzed serum hepcidin in 111 infants born after $32+0$ to $36+6$ wk gestational age during the first 4 mo of life.

RESULTS: Hepcidin concentrations decreased during the first 4 mo of life, and concentrations were lower in infants with ID compared to those without ID. Infants who developed ID at the age of 4 mo had already significantly lower levels of hepcidin at 1.5 mo of age, while ferritin was already significantly lower at the age of $1 \mathrm{wk}$.

CONCLUSION: Hepcidin concentrations of late preterm infants decrease during the first $4 \mathrm{mo}$ of life. This decrease, which parallels a decrease of ferritin concentration, we interpret as a physiological response, aiming to increase iron availability. Hepcidin concentrations are lower in infants with ID compared with those without ID, with a notable change already observed at $1.5 \mathrm{mo}$ of age. Hepcidin can be used as an early marker of ID, although an additive value of hepcidin over ferritin in the diagnosis of ID is not present.

\section{INTRODUCTION}

Preterm infants are susceptible to iron deficiency (ID) because of their compromised iron stores at birth, high postnatal growth rate, and iatrogenic phlebotomy losses. ID in infancy is associated with long-term neurodevelopmental impairment, despite adequate iron treatment $(1,2)$. Therefore, prevention of ID is important for optimal development of preterm infants.

Since iron cannot be actively excreted, regulation of its absorption is essential to maintain systemic iron homeostasis. Hepcidin, a peptide hormone produced mainly in the liver, plays a central role in the regulation of iron absorption and body iron distribution (3). Hepcidin binds to the iron-transporting protein ferroportin, causing its internalization and degradation, thereby decreasing iron transfer from hepatocytes, macrophages, and absorptive enterocytes to the blood (4). As a result, dietary iron absorption and circulating iron in the blood decrease, whereas intracellular iron stores increase (5). Hepcidin transcription is decreased in cases of ID, hypoxia, and increased erythropoiesis, and it is increased during infection, inflammation, and iron overload $(6,7)$. In a previous trial of marginally preterm and term low-birth-weight infants, significantly lower hepcidin concentrations were observed in infants with ID compared with iron-replete infants, and it was suggested that hepcidin may be a good additional indicator of ID in preterm infants (8). However, in that study, the majority of the iron-replete infants received iron supplementation. Whether higher hepcidin concentrations in these iron-replete infants represent a physiologic increase, or an upregulation in response to iron supplementation, is unclear (8). In the Netherlands, late preterm infants do not routinely receive iron supplementation. The aim of this study was therefore to investigate changes in hepcidin concentrations during the first 4 mo of life in a population of Dutch, late preterm infants. We hypothesized that hepcidin concentrations decrease during the first 4 mo of life, as a response to lower iron stores and that hepcidin concentrations are lower in infants with ID compared with infants without ID at the age of $4 \mathrm{mo}$. In a secondary analysis, we aimed to investigate associations between hepcidin and the type of feeding, other indicators of iron status, and erythropoiesis.

\section{RESULTS}

\section{Study Population}

Of the 200 eligible infants, 21 infants met the exclusion criteria, and in 44 infants blood samples were not analyzed because of increased C-reactive protein (CRP) concentrations $(n=$ $17)$ or incomplete analyses $(n=27)$ (Figure 1). Twenty-four parents decided to withdraw their child from the study during the follow-up period, because of resistance against blood sampling $(n=7)$, follow-up visits in another hospital for logistic reasons $(n=10)$, or without giving any reason $(n=7)$. Of the included infants $(n=111), 61.3 \%$ were boys. Our study population was representative of the Dutch population considering educational level (9). Ethnicity of our study population

\footnotetext{
'Department of Pediatrics, OLVG, Amsterdam, the Netherlands; ${ }^{2}$ Department of Clinical Sciences, Pediatrics, Umeå University, Umeå, Sweden; ${ }^{3}$ Department of Pediatrics, Medical Center Alkmaar, Alkmaar, The Netherlands; ${ }^{4}$ Department of Pediatrics, Medical Center Haaglanden, The Hague, The Netherlands; ${ }^{5}$ Department of Pediatrics, VU University Medical Center, Amsterdam, the Netherlands; ${ }^{6}$ Department of Clinical Chemistry, LabWest, HAGA Teaching Hospital, The Hague, The Netherlands; ${ }^{7}$ Department of Pediatrics, VU University Medical Center, Amsterdam, the Netherlands; ${ }^{8}$ Department of Pediatrics, Emma Children's Hospital - Academic Medical Center, Amsterdam, the Netherlands. Correspondence: Lieke Uijterschout (l.uijterschout@gmail.com)

Received 30 June 2015; accepted 24 September 2015; advance online publication 24 February 2016. doi:10.1038/pr.2015.258
} 


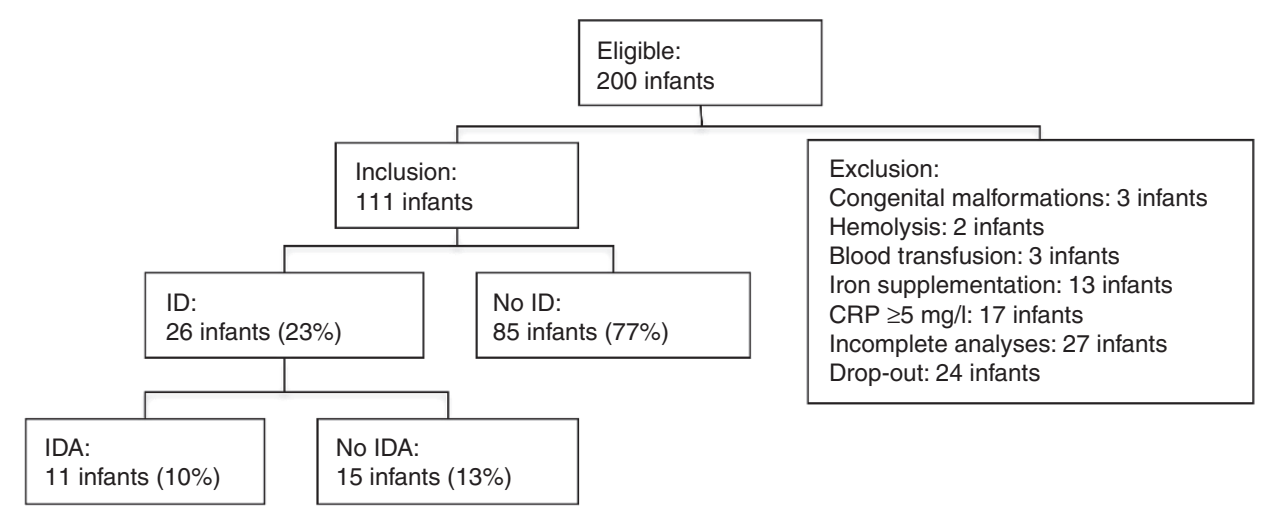

Figure 1. Flowchart of the study population.

Table 1. Characteristics of the study population

\begin{tabular}{lcccc}
\hline Variable & Number & Percentage & Mean & $95 \% \mathrm{Cl}$ \\
\hline Gender (male) & 68 & 61 & NA & NA \\
Gestational age (weeks) & 111 & NA & 35.0 & $33.1-36.8$ \\
Birth weight (g) & 111 & NA & 2,345 & $1,613-3,138$ \\
Birth weight (Z-score) & 111 & NA & -0.25 & $-1.63-1.43$ \\
Small for gestational age & 17 & 15 & NA & NA \\
$\begin{array}{l}\text { Apgar score at 5 minutes } \\
\text { Ethnicity (western) }\end{array}$ & 111 & NA & 9 & $6-10$ \\
$\begin{array}{l}\text { Educational level of the } \\
\text { mother (high) }\end{array}$ & 40 & 54 & NA & NA \\
$\begin{array}{l}\text { Exclusively breastfeeding } \\
\text { at 1.5 mo of age }\end{array}$ & 32 & 41 & NA & NA \\
$\begin{array}{l}\text { Exclusively breastfeeding } \\
\text { at 4 mo of age }\end{array}$ & 18 & 16 & NA & NA \\
\end{tabular}

$\mathrm{Cl}$, confidence interval, NA, not applicable.

was representative of the multi-ethnic population living in the urbanized, western region of the Netherlands (10). Mean GA and birth weight were $35.0 \mathrm{wk}$ (95\% confidence interval (CI): 33.1-36.8) and 2,145g (95\% CI: 1,613-3,138), respectively, (Table 1). The most frequently observed neonatal diagnoses were jaundice $(n=29(26 \%))$ and respiratory disorders $(n=$ $22(20 \%))$. ID and iron deficiency anemia were present in 26 (23\%) and $11(10 \%)$ infants at the age of 4 mo, respectively (Figure 1).

\section{Hepcidin at $1 \mathrm{Wk}, 1.5 \mathrm{Mo}$, and 4 Mo}

Median hepcidin concentrations were $74.0 \mathrm{ng} / \mathrm{ml}$ (95\% CI: $14.7-171.3), 33.1 \mathrm{ng} / \mathrm{ml}$ (95\% CI: 9.6-94.0), and $17.7 \mathrm{ng} /$ $\mathrm{ml}$ (95\% CI: 3.6-48.1) at the age of $1 \mathrm{wk}, 1.5 \mathrm{mo}$, and $4 \mathrm{mo}$, respectively (Figure 2). Hepcidin concentrations in blood samples obtained in the morning were similar compared to those obtained in the afternoon, and we found no association between hepcidin and time of blood sampling as a continuous variable. Hepcidin was significantly lower in males than in females at the age of $1 \mathrm{wk}$ (geometric mean was $58.0 \mathrm{ng} /$ $\mathrm{ml}$ (95\% CI: $14.3-155.9)$ vs. $82.2 \mathrm{ng} / \mathrm{ml}$ (95\% CI: $20.2-198.7$; $P=0.03)$, and this difference persisted after adjustment for the following potential confounding factors: time of blood

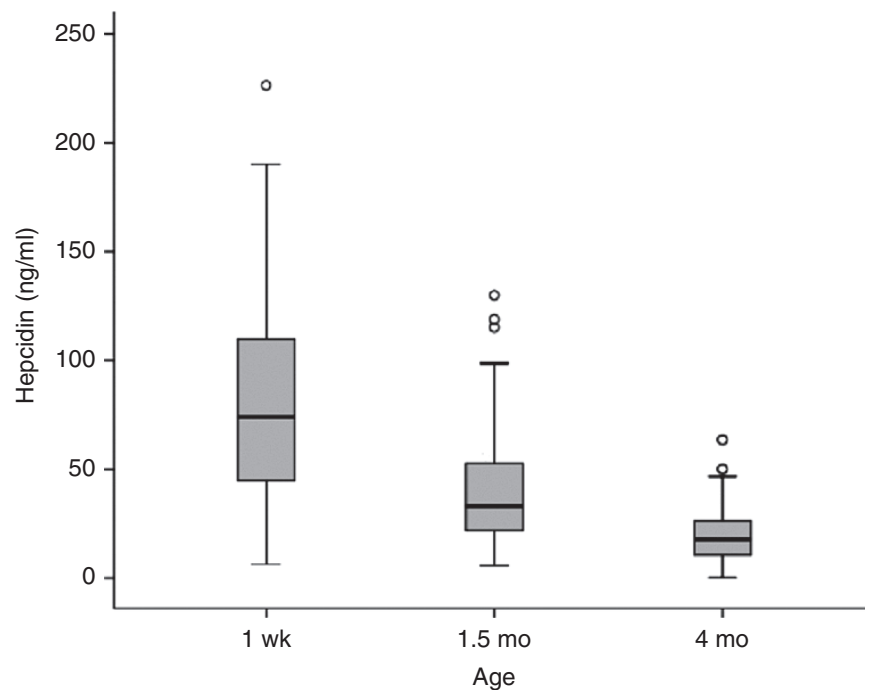

Figure 2. Box plots representing the median, upper and lower quartiles and the 1.5 interquartile range of hepcidin concentrations at the age of $1 \mathrm{wk}, 1.5 \mathrm{mo}$, and $4 \mathrm{mo}$, respectively. Outliers are represented as dots.

sampling, gestational age, birth weight, ferritin, $\mathrm{Hb}$, reticulocytes, and type of feeding. The difference in hepcidin concentrations between males and females became smaller with increasing age and was no longer significant at the age of 1.5 and 4 mo (data not shown).

\section{Hepcidin and Other Variables as Predictors of ID at 4 Mo}

The observed decrease in hepcidin was more pronounced in infants who developed ID at 4 mo with significant differences at the age of 1.5 and 4 mo (Table 2 and Figure 3). Similarly, hemoglobin, but neither Ret-Hb nor reticulocytes, differed between ID and no-ID cases from $1.5 \mathrm{mo}$. At the age of $1 \mathrm{wk}$, ferritin was the only biomarker that was already significantly lower in infants who became ID at the age of $4 \mathrm{mo}$, compared with infants without ID at that age (Table 2). We constructed a receiver-operating characteristic curve to investigate the predictive value of hepcidin and ferritin at the age of $1 \mathrm{wk}$ and 1.5 mo for the development of ID at the age of $4 \mathrm{mo}$. At the age of $1 \mathrm{wk}$, a cutoff value of hepcidin $<56 \mathrm{ng} / \mathrm{ml}$ provided the most balanced sensitivity and specificity of 68.7 and $55.6 \%$, respectively (area under the curve 0.648). This was low compared 
Table 2. Mean concentrations of hepcidin and indicators of iron status and erythropoiesis in late preterm infants with iron deficiency at the age of 1 week, 1.5 mo and 4 mo, respectively

\begin{tabular}{|c|c|c|c|c|c|}
\hline & $\begin{array}{c}\text { ID } \\
(n=26)\end{array}$ & $95 \% \mathrm{Cl}$ & $\begin{array}{c}\text { No ID } \\
(n=85)\end{array}$ & $95 \% \mathrm{Cl}$ & $P$ \\
\hline \multicolumn{6}{|c|}{ Hepcidin $(\mathrm{ng} / \mathrm{ml})^{*}$} \\
\hline $1 \mathrm{wk}$ & 51.7 & $14.8-149.6$ & 69.6 & $14.6-180.1$ & 0.12 \\
\hline $1.5 \mathrm{mo}$ & 19.9 & $5.8-58.3$ & 40.3 & $15.1-106.6$ & $<0.001$ \\
\hline $4 \mathrm{mo}$ & 7.7 & $0.3-37.7$ & 20.2 & $8.6-49.1$ & $<0.001$ \\
\hline \multicolumn{6}{|c|}{ Ferritin $(\mu \mathrm{g} / \mathrm{l})^{*}$} \\
\hline $1 \mathrm{wk}$ & 95.8 & $32.2-287.7$ & 177.9 & $37.1-469.2$ & 0.001 \\
\hline $1.5 \mathrm{mo}$ & 51.0 & $13.2-127.1$ & 122.7 & $36.4-315.5$ & $<0.001$ \\
\hline $4 \mathrm{mo}$ & 13.2 & $3.6-19.0$ & 40.1 & $20.0-112.3$ & $<0.001$ \\
\hline \multicolumn{6}{|c|}{ Hemoglobin ( $g / l)$} \\
\hline $1 \mathrm{wk}$ & 165.4 & $120.7-215.7$ & 169.2 & $130.4-223.8$ & 0.51 \\
\hline $1.5 \mathrm{mo}$ & 96.6 & $77.7-122.8$ & 104.8 & $81.7-132.0$ & 0.02 \\
\hline $4 \mathrm{mo}$ & 105.9 & $79.1-130.8$ & 113.1 & $98.2-128.3$ & 0.001 \\
\hline \multicolumn{6}{|c|}{ Ret-Hb (pg) } \\
\hline $1 \mathrm{wk}$ & 29.1 & $24.3-33.2$ & 30.2 & $24.4-36.0$ & 0.15 \\
\hline $1.5 \mathrm{mo}$ & 29.8 & $25.2-32.6$ & 30.4 & $26.5-33.5$ & 0.21 \\
\hline $4 \mathrm{mo}$ & 27.2 & $16.9-33.4$ & 28.3 & $23.9-31.5$ & 0.09 \\
\hline \multicolumn{6}{|c|}{ Reticulocytes (\%o) } \\
\hline $1 \mathrm{wk}$ & 27.2 & $7.3-59.0$ & 38.0 & $10.5-80.8$ & 0.19 \\
\hline $1.5 \mathrm{mo}$ & 21.5 & $9.8-36.0$ & 18.5 & $7.8-32.5$ & 0.12 \\
\hline $4 \mathrm{mo}$ & 9.7 & $6.0-16.3$ & 9.8 & $5.0-16.4$ & 0.88 \\
\hline
\end{tabular}

$\mathrm{Cl}$, confidence interval; ID, iron deficiency.

with ferritin that provided a sensitivity and specificity of 80.6 and $85.6 \%$, respectively, at a cutoff value of $115 \mu \mathrm{g} / \mathrm{l}$ (area under the curve 0.779). At the age of $1.5 \mathrm{mo}$, the predictive value of hepcidin for the development of ID at the age of 4 mo was similar compared to ferritin (sensitivity and specificity of 82.4 and $73.9 \%$ at a cutoff value of hepcidin $<26 \mathrm{ng} / \mathrm{ml}$ (area under the curve 0.813 ) and a sensitivity and specificity of 83.8 and $65.2 \%$ at a cutoff level of ferritin $<88 \mu \mathrm{g} / \mathrm{l}$ (area under the curve 0.852$)$ ).

\section{The Effect of the Type of Feeding on Hepcidin Concentrations}

At the age of $4 \mathrm{mo}$, hepcidin concentrations were significantly lower in infants who were exclusively breastfed compared with those who received formula exclusively or in combination with breast milk $(6.8 \mathrm{ng} / \mathrm{ml}(95 \%$ CI: $0.1-34.5)$ vs. $19.0 \mathrm{ng} / \mathrm{ml}(95 \%$ CI: 7.4-50.0), $P<0.001)$. Furthermore, hepcidin was negatively associated with the duration of exclusive breastfeeding $\left(\beta=-0.443 ; P<0.001 ; R^{2}=19.6 \%\right)$, This association persisted after adjustment for gender, indicators of iron status (ferritin, $\mathrm{Hb}$, Ret-Hb), and reticulocytes.

\section{Correlations Between Hepcidin, Other Indicators of Iron Status, and Reticulocytes}

Results of linear regression analyses showed that hepcidin was associated with all indicators of iron status (ferritin, Hb,

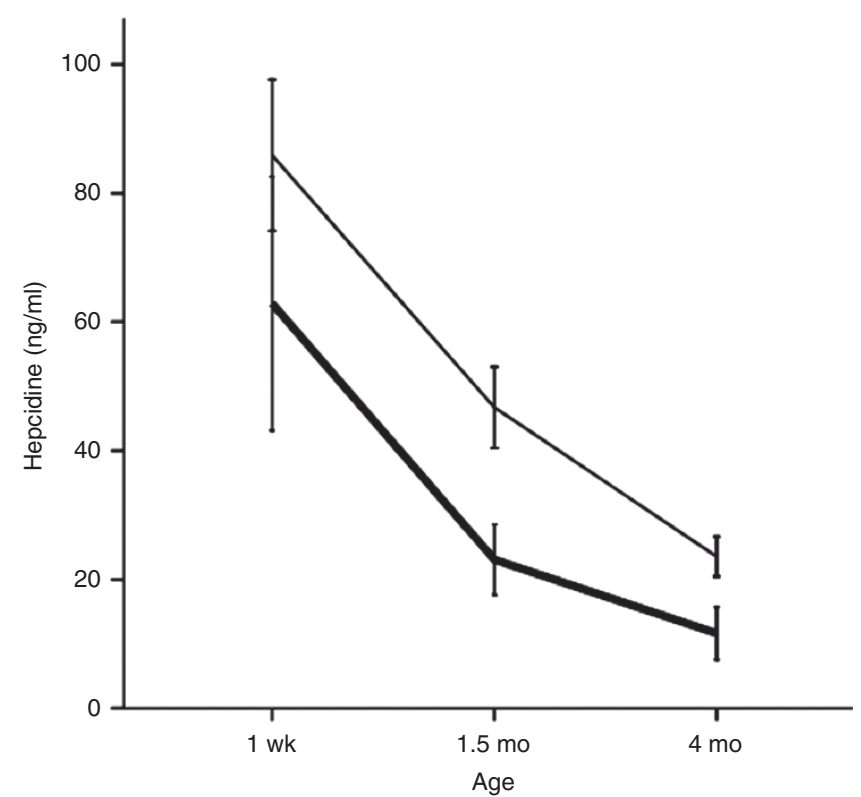

Figure 3. Geometric mean concentrations of hepcidin $(\mathrm{ng} / \mathrm{ml})$ at the age of $1 \mathrm{wk}(n=87), 1.5 \mathrm{mo}(n=93), 4 \mathrm{mo}(n=111)$ in infants who became ID at the age of $4 \mathrm{mo}$ and infant without ID at the age of $4 \mathrm{mo}$. Error bars represent $95 \%$ confidence interval. * Significant at level $<0.001$. Thick line indicates ID. Thin line indicates no ID.

ret- $\mathrm{Hb}$ ) at the age of 1.5 and 4 mo, respectively (Table 3 ). For reticulocytes, there was a significant negative association at the age of $1.5 \mathrm{mo}$. Ferritin was the strongest predictor of hepcidin and was always included in the best predicting model (Table 3). Results of multivariate analyses showed that the predictive value of ferritin, $\mathrm{Hb}$, ret- $\mathrm{Hb}$, and reticulocytes for hepcidin was $18.3,55.5$, and $42.9 \%$ at the age of $1 \mathrm{wk}, 1.5 \mathrm{mo}$, and 4 mo, respectively. No interacting effect was observed when age was included in the model.

\section{DISCUSSION}

To the best of our knowledge, this is the first study describing hepcidin concentrations from birth to the age of $4 \mathrm{mo}$ in late-preterm infants who received no iron supplementation. This study showed that hepcidin concentrations decrease during the first 4 mo of life in late preterm infants, both in those who later develop ID as well as in those who were iron-replete at 4 mo of age. Furthermore, we found that infants who developed ID at 4 mo of age had significantly lower hepcidin concentrations already at $1.5 \mathrm{mo}$ of age, suggesting that hepcidin is a predictor of later ID. In addition, we observed that, irrespective of ferritin and $\mathrm{Hb}$, hepcidin concentrations in infants who were exclusively breastfed for 4 mo were significantly lower compared to those who received formula exclusively or in combination with breast milk at the age of $4 \mathrm{mo}$. Unexpectedly, we found that hepcidin was significantly lower in males compared to females in the first week of life and that in contrast to results reported in older children and adults (11), hepcidin concentrations in our population of late-preterm infants were not affected by a circadian rhythm. 
Table 3. Results of univariate and multivariate linear regression models assessing the relation of hepcidin with ferritin, hemoglobin, Ret-Hb, and reticulocytes in late preterm infants at the age of $1 \mathrm{wk}, 1.5 \mathrm{mo}$, and $4 \mathrm{mo}$, respectively.

\begin{tabular}{|c|c|c|c|c|c|c|c|c|c|}
\hline \multirow[b]{3}{*}{ Age } & \multicolumn{9}{|c|}{$\log _{10}$ hepcidin $(\mathrm{ng} / \mathrm{ml})$} \\
\hline & \multicolumn{3}{|c|}{$1 \mathrm{wk}$} & \multicolumn{3}{|c|}{$1.5 \mathrm{mo}$} & \multicolumn{3}{|c|}{$4 \mathrm{mo}$} \\
\hline & $\beta$ & $R^{2}$ & $P$ & $\beta$ & $R^{2}$ & $P$ & $\beta$ & $R^{2}$ & $P$ \\
\hline Hemoglobin (g/l) & -0.174 & 3.0 & 0.11 & 0.223 & 5.0 & 0.03 & 0.328 & 10.8 & $<0.001$ \\
\hline Ret-Hb (pg) & 0.003 & 0.0 & 0.98 & 0.291 & 8.5 & 0.005 & 0.425 & 18.0 & $<0.001$ \\
\hline \multicolumn{10}{|l|}{ Multivariate regression } \\
\hline $\log _{10}$ ferritin, reticulocytes & & 18.3 & $<0.001$ & & & & & & \\
\hline $\log _{10}$ ferritin, reticulocytes & & & & & 55.5 & $<0.001$ & & & \\
\hline $\log _{10}$ ferritin, Ret-Hb & & & & & & & & 42.9 & $<0.001$ \\
\hline
\end{tabular}

Infants who developed ID at 4 mo of age had significantly lower hepcidin concentrations already at 1.5 mo of age compared to infants without ID at the age of 4 mo. These results suggest that hepcidin could be a promising predictor of later ID in late preterm infants with no concomitant infection/ inflammation. However, the additive value of hepcidin over ferritin in the diagnosis of ID is yet questionable, since ferritin was the most important predictor of hepcidin at all times of measures. This is similar to results reported in previous studies in both children and adults $(8,12)$. Furthermore, differences in ferritin between infants with and those without ID at the age of 4 mo were present already at the age of $1 \mathrm{wk}$, whereas no differences were observed in hepcidin concentrations at that age. Moreover, the diagnostic value of hepcidin is limited by the absence of measurement standardization (13) and age-specific reference values for hepcidin in infants younger than $6 \mathrm{mo}$ of age. Studies on harmonization of hepcidin assays in general, and definition of reference values in infants younger than $6 \mathrm{mo}$ of age are required in order to investigate the potential value of hepcidin in the diagnosis of ID in preterm infants.

Hepcidin concentrations in our population decreased during the first 4 mo of life. A similar decrease in hepcidin from the age of $6 \mathrm{wk}$ to $1 \mathrm{y}$ has been observed in term infants with no iron deficiency anemia (ferritin $>12 \mu \mathrm{g} / \mathrm{l}$ and $\mathrm{Hb}>105 \mathrm{~g} / \mathrm{l}$ at 3 and $6 \mathrm{mo}$ and $>100 \mathrm{~g} / \mathrm{l}$ at $12 \mathrm{mo}$ ) (14). This decrease in hepcidin was accompanied by a similar decrease in concentrations of ferritin, and this previously described correlation between both biomarkers was not influenced by age. These results suggest that hepcidin concentrations decrease in response to a decrease in ferritin, in order to mobilize iron stores, and increase dietary iron absorption. Such a response is justifiable since these infants are at risk of ID and iron absorption and availability for erythropoiesis and tissue expansion needs to be maximized during the first year of life. This hypothesis is further supported by our observation of lower hepcidin concentrations in exclusively breastfed infant compared to those receiving formula with or without breast milk. Since the iron content in breast milk is lower compared to formula (15), low hepcidin concentrations in exclusively breastfed infants will optimize the absorption of the limited amount of iron in breast milk. The association between hepcidin and the duration of breastfeeding, irrespective of ferritin concentrations, illustrates that hepcidin is influenced by both iron stores and dietary iron intake, but maybe also by some not yet described mechanism induced by iron intake.

Hepcidin concentrations were significantly lower in males than in females in the first week of life. This gender difference became smaller with increasing age and was no longer significant at the age of 1.5 and 4 mo, respectively. Significant differences in hepcidin concentrations between males and females have been previously reported in adults $(12,16)$ and 6-mo-old Kenyan infants (17). In these infants, lower hepcidin concentrations in males were mainly explained by the lower overall iron status in males, and higher CRP concentration in females (17). However, we observed no differences in either iron status indicators or CRP between males and females, and the gender difference may have other explanations. In adults, testosterone is the major hormone responsible for the observed gender differences in the regulation of iron metabolism (18). Testosterone may repress hepcidin transcription by enhancing epidermal growth factor receptor signaling in the liver (19) or by stimulating erythropoietin production (20). Interestingly, a transient activation of the hypothalamic-pituitary-gonadal axis has been observed in males during the first months of life (21), and there is some evidence of even higher gonadotropin and testosterone levels in preterm compared with full-term infants (22-24). We hypothesize that higher testosterone levels in preterm males may suppress hepcidin concentrations shortly after birth. However, more studies on the association between testosterone and hepcidin are needed to confirm the presence of such a gender difference and to investigate this hypothesis.

In contrast to results reported in older children and in adults (11), we found no circadian rhythm in hepcidin concentrations. Studies on hepcidin in preterm infants are few $(8,25)$ and to our concern, none investigated diurnal variation in 
hepcidin. In adults, lowest hepcidin concentrations have been observed in the early morning, and concentrations steadily increase throughout the day before declining during the evening hours (16). This pattern was neither influenced by food intake (11), nor by the sleep-wake cycle (26). It has been suggested that the transcriptional regulators related to genes involved in circadian rhythm (upstream stimulatory factor 1 (USF1) and USF2), are potentially significant modulators of hepcidin expression $(26,27)$. Furthermore, diurnal variation in hepcidin might also be secondary to innate circadian rhythm of one of the many biological determinants of serum hepcidin concentrations $(3,11)$. The absence of this circadian rhythm in hepcidin concentrations in preterm infants warrants further investigation.

In this study, we demonstrated for the first time that in a population of late-preterm infants where iron supplementation was not used, hepcidin decreased during the first 4 mo of life. This decrease, which parallels a decrease of ferritin concentration, we interpret as a physiological response, aiming to increase iron availability. These results illustrate the increased iron requirements in preterm infants. Therefore, preterm infants with a birth weight $<2,500 \mathrm{~g}$ should receive iron supplementation according to current guidelines (28). Furthermore, the results of this study confirm that hepcidin concentrations are lower in infants with ID compared to those without ID, with a notable change already observed at 1.5 mo of age. Hepcidin can be used as an early marker of ID, although an additive value of hepcidin over ferritin in the diagnosis of ID is not present. Standardization of hepcidin assays in general, and definition of reference values for hepcidin in infants younger than $6 \mathrm{mo}$ of age are needed in order to investigate the potential diagnostic value in the diagnosis of ID in preterm as well as term infants. In addition, the observed absence of a circadian rhythm, the association to diet, and the presence of a gender difference in hepcidin concentrations prompts further studies.

\section{METHODS}

\section{Study Design}

A prospective observational trial of 200 late-preterm infants with the focus on iron status development was conducted (29). We present hepcidin concentrations and its correlation to the type of feeding, and other indicators of iron status.

\section{Study Population}

Preterm infants born between $32+0$ and $36+6$ wk of gestational age (GA) were included in the study between March 2011 and April 2013. Eligible infants were identified from delivery records. Parents were contacted at the hospital within 7 days after delivery, and written and oral information was provided by the investigators (M.A., L.U.). Exclusion criteria were congenital malformations, chronic or inherited metabolic disease, hemoglobinopathies, active blood loss during delivery/ major bleeding, twin-to-twin transfusion syndrome, hemolytic disease, (positive coombs), the use of iron supplementation, or blood transfusions. The study was approved by the Medical Ethics Committee of South-West Holland. All parents of the participating infants gave written informed consent.

\section{Data Collection}

Infants visited the outpatient clinic for routine follow-up at the postnatal age of 1.5 and $4 \mathrm{mo}$, respectively. In the first week of life and at every follow-up visit, venous blood was collected $(3 \mathrm{ml})$ and analyzed for hepcidin and iron status biomarkers (ferritin, hemoglobin $(\mathrm{Hb})$, reticulocyte hemoglobin content (Ret-Hb)), reticulocytes, and CRP. Reticulocytes were measured as a marker of erythropoiesis. CRP was measured to detect cases of infection or inflammation, which usually is accompanied by an increase in hepcidin and ferritin concentrations. Blood samples were considered as incomplete when insufficient blood was available to measure hepcidin, ferritin, and $\mathrm{Hb}$ at the age of $4 \mathrm{mo}$. We defined ID as a ferritin $<20 \mu \mathrm{g} / \mathrm{l}$ at the age of $4 \mathrm{mo}(30)$. Iron deficiency anemia was defined as ID in combination with anemia, defined as hemoglobin $(\mathrm{Hb})<105 \mathrm{~g} / \mathrm{l}(29)$.

We documented the type of feeding that infants received at the age of 1.5 and 4 mo respectively, by using an unstandardized questionnaire. Exclusive breastfeeding was defined as the use of breastfeeding and water but no formula or complementary foods. Exclusive formula was defined as formula feeding and water, but no breastfeeding or complementary foods. Anthropometric data were recorded after birth, and at the postnatal age of 1.5 and $4 \mathrm{mo}$, respectively; length was measured to the nearest millimeter by using a length board, weight was measured to the nearest $0.001 \mathrm{~kg}$ by using a digital scale, and head circumference was measured to the nearest millimeter by using a plastic measuring tape. Z-scores for anthropometric data were calculated with correction for GA at birth, by using Dutch references (31). Perinatal data (Apgar scores, gestational age, and neonatal diagnoses) were collected from delivery records and medical files at inclusion. In this study, obstetricians performed early cord clamping (<60s) (32), which was the standard procedure at time of the study. Parents filled out a questionnaire concerning demographic data and parental education. When both parents were born in a western country (Europe, United States) infants were classified as "western." Educational level of the parents was classified as "high" when they completed higher vocational education or university.

\section{Biochemical Analysis}

Venous blood was collected with EDTA and a serum tube. Blood samples were drawn between 7 am and $8 \mathrm{pm}$, and time of blood sampling was recorded. Ferritin and CRP were determined in plasma, using a Unicel DxI 800 immunochemistry analyzer (Beckman Coulter, Brea, $\mathrm{CA})$. Hb, Ret-Hb, and reticulocytes were determined using Sysmex XE 5000 (Sysmex, Kobe, Japan) automated hematology analyzers. Samples were centrifuged, and serum was aliquoted and frozen at $-80{ }^{\circ} \mathrm{C}$ until measurement of hepcidin after one freeze-thaw cycle. Hepcidin was determined by enzyme-linked immunoassay (ELISA) (Human hepcidin, extraction-free, EIA kit, Cat. No S-1337, Batch No: A11599, Bachem, Peninsula Laboratories, San Carlos, CA) in accordance with the manufacturer's instructions. According to the manufacturer, this ELISA is specific for the hepcidin-25, the bioactive form of hepcidin that can block the iron transporter ferroportin. Before analysis of hepcidin, the serum samples were diluted 1:6 in treated human serum provided with the kit. Hepcidin-25 levels were calculated from a calibration curve with a linear measuring range near the IC50 of the curve $(1.5 \mathrm{ng} / \mathrm{ml}$, range: $0.35-1.72)$. Samples with coefficient of variants above $15 \%$ or with levels falling outside the measuring range were re-assayed in a different dilution. We calculated an intra- and inter-assay variation of $<10$ and $<15 \%$, respectively.

\section{Statistical Analysis}

The original study aim was to establish the prevalence of ID in late preterm infants and to identify risk factors for ID. The study was powered to detect a prevalence of ID of $10 \%$ (33), with $95 \%$ confidence limits of $\pm 5 \%$ and a dropout rate of $20 \%$. Statistical package for the Social Sciences (SPSS) (version 21.0; SPSS, Chicago, IL) was used for statistical analysis. Before analysis, data were checked on normal distribution using histograms and Kolmogorov-Smirnov test. Because hepcidin and ferritin showed skewed distributions, they were log transformed for all statistical calculations. These biomarkers were normally distributed on a logarithmic scale. For interpretation, the values were converted back to the original units as geometric means and SD. Blood sampling time was categorized in two groups; before and after $12 \mathrm{pm}$, in line with previously reported serum hepcidin concentration patterns throughout the day $(11,12)$. To preclude the influence of infection/inflammation on concentrations of hepcidin and other iron status biomarkers, all samples with a CRP $\geq 5 \mathrm{mg} / \mathrm{l}$ were not further analyzed (34). Comparisons of hepcidin and indicators 
of iron status and reticulocytes over time were performed by using a paired $t$-test. For comparisons between groups, we used a Student's $t$-test for continuous variables and Chi-square test for dichotomous variables. Relations between hepcidin and type of feeding, other indicators of iron status and reticulocytes were explored with univariate and multivariate linear regression models, using a backward Wald method. A general estimating equation for repeated measurements with a linear regression model was used to analyze the association between hepcidin, age, and ferritin. Statistical significance was defined as a $P$ value $<0.05$.

\section{ACKNOWLEDGMENTS}

We thank the children and parents who participated in this study. We thank the staff of the neonatal departments of the Juliana Children's Hospital, Medical Center Haaglanden, and Medical Center Alkmaar for their assistance including children for this study.

\section{STATEMENT OF FINANCIAL SUPPORT}

Hepcidin analyses were financed by Nutricia Research Foundation. Nutricia had no role in the study design, analysis, or interpretation of the data; writing the manuscript; or the decision to submit the paper for publication.

Disclosure: The authors have nothing to disclose.

\section{REFERENCES}

1. Lozoff B, Jimenez E, Smith JB. Double burden of iron deficiency in infancy and low socioeconomic status: a longitudinal analysis of cognitive test scores to age 19 years. Arch Pediatr Adolesc Med 2006;160:1108-13.

2. Beard J. Recent evidence from human and animal studies regarding iron status and infant development. J Nutr 2007;137:524S-530S.

3. Kroot JJ, Tjalsma H, Fleming RE, Swinkels DW. Hepcidin in human iron disorders: diagnostic implications. Clin Chem 2011;57:1650-69.

4. Nemeth E, Tuttle MS, Powelson J, et al. Hepcidin regulates cellular iron efflux by binding to ferroportin and inducing its internalization. Science 2004;306:2090-3.

5. Ganz T, Nemeth E. Hepcidin and iron homeostasis. Biochim Biophys Acta 2012;1823:1434-43.

6. Ganz T, Nemeth E. Regulation of iron acquisition and iron distribution in mammals. Biochim Biophys Acta 2006;1763:690-9.

7. Ganz T, Nemeth E. Iron sequestration and anemia of inflammation. Semin Hematol 2009;46:387-93.

8. Berglund S, Lönnerdal B, Westrup B, Domellöf M. Effects of iron supplementation on serum hepcidin and serum erythropoietin in low-birthweight infants. Am J Clin Nutr 2011;94:1553-61.

9. Verweij A, Sanders C, van der Lucht F, and den Hartog FRJ. [Training and education: what is the current situation?] Nationaal Kompas, 2014. (http:// www.nationaalkompas.nl/bevolking/sociaaleconomische-status/wat-issociaaleconomische-status/.)

10. Centraal Bureau voor de Statistiek. [Migration; country of origin, homeland and gender] Centraal Bureau voor de statistiek, 2015. (http://statline. cbs.nl/StatWeb/publication/?VW=T\&DM=SLNL\&PA=60032\&LA=NL.)

11. Schaap CC, Hendriks JC, Kortman GA, et al. Diurnal rhythm rather than dietary iron mediates daily hepcidin variations. Clin Chem 2013;59:527-35.

12. Galesloot TE, Vermeulen SH, Geurts-Moespot AJ, et al. Serum hepcidin: reference ranges and biochemical correlates in the general population. Blood 2011;117:e218-25.

13. Kroot JJ, van Herwaarden AE, Tjalsma H, Jansen RT, Hendriks JC, Swinkels DW. Second round robin for plasma hepcidin methods: first steps toward harmonization. Am J Hematol 2012;87:977-83.

14. Mupfudze TG, Stoltzfus RJ, Rukobo S, Moulton LH, Humphrey JH, Prendergast AJ; SHINE Project Team. Hepcidin decreases over the first year of life in healthy African infants. Br J Haematol 2014;164:150-3.

15. Dube K, Schwartz J, Mueller MJ, Kalhoff H, Kersting M. Iron intake and iron status in breastfed infants during the first year of life. Clin Nutr 2010;29:773-8.
16. Wisaksana R, de Mast Q, Alisjahbana B, et al. Inverse relationship of serum hepcidin levels with CD4 cell counts in HIV-infected patients selected from an Indonesian prospective cohort study. PLoS One 2013;8: e79904.

17. Jaeggi T, Moretti D, Kvalsvig J, et al. Iron status and systemic inflammation, but not gut inflammation, strongly predict gender-specific concentrations of serum hepcidin in infants in rural Kenya. PLoS One 2013;8:e57513.

18. Bachman E, Feng R, Travison T, et al. Testosterone suppresses hepcidin in men: a potential mechanism for testosterone-induced erythrocytosis. J Clin Endocrinol Metab 2010;95:4743-7.

19. Latour C, Kautz L, Besson-Fournier C, et al. Testosterone perturbs systemic iron balance through activation of epidermal growth factor receptor signaling in the liver and repression of hepcidin. Hepatology 2014;59: 683-94.

20. Bachman E, Travison TG, Basaria S, et al. Testosterone induces erythrocytosis via increased erythropoietin and suppressed hepcidin: evidence for a new erythropoietin/hemoglobin set point. J Gerontol A Biol Sci Med Sci 2014;69:725-35.

21. Alexander GM. Postnatal testosterone concentrations and male social development. Front Endocrinol (Lausanne) 2014;5:15.

22. Forest MG, de Peretti E, Bertrand J. Testicular and adrenal androgens and their binding to plasma proteins in the perinatal period: developmental patterns of plasma testosterone, 4-androstenedione, dehydroepiandrosterone and its sulfate in premature and small for date infants as compared with that of full-term infants. J Steroid Biochem 1980;12:25-36.

23. Tapanainen J, Koivisto M, Vihko R, Huhtaniemi I. Enhanced activity of the pituitary-gonadal axis in premature human infants. J Clin Endocrinol Metab 1981;52:235-8.

24. Kuiri-Hänninen T, Seuri R, Tyrväinen E, et al. Increased activity of the hypothalamic-pituitary-testicular axis in infancy results in increased androgen action in premature boys. J Clin Endocrinol Metab 2011;96: 98-105.

25. Müller KF, Lorenz L, Poets CF, Westerman M, Franz AR. Hepcidin concentrations in serum and urine correlate with iron homeostasis in preterm infants. J Pediatr 2012;160:949-53.e2.

26. Troutt JS, Rudling M, Persson L, et al. Circulating human hepcidin-25 concentrations display a diurnal rhythm, increase with prolonged fasting, and are reduced by growth hormone administration. Clin Chem 2012;58:1225-32.

27. Bayele HK, McArdle H, Srai SK. Cis and trans regulation of hepcidin expression by upstream stimulatory factor. Blood 2006;108:4237-45.

28. Bhatia J, Griffin I, Anderson D, Kler N, Domellöf M. Selected macro/ micronutrient needs of the routine preterm infant. J Pediatr 2013;162: Suppl 3:S48-55.

29. Uijterschout L, Domellöf M, Abbink M, et al. Iron deficiency in the first 6 months of age in infants born between 32 and 37 weeks of gestational age. Eur J Clin Nutr 2015;69:598-602.

30. Domellöf M, Braegger C, Campoy C, et al.; ESPGHAN Committee on Nutrition. Iron requirements of infants and toddlers. J Pediatr Gastroenterol Nutr 2014;58:119-29.

31. Schönbeck Y, Talma H, van Dommelen P, et al. The world's tallest nation has stopped growing taller: the height of Dutch children from 1955 to 2009. Pediatr Res 2013;73:371-7.

32. McDonald SJ, Middleton P, Dowswell T, Morris PS. Effect of timing of umbilical cord clamping of term infants on maternal and neonatal outcomes. Cochrane Database Syst Rev 2013;7:CD004074.

33. Schiza V, Giapros V, Pantou K, Theocharis P, Challa A, Andronikou S. Serum transferrin receptor, ferritin, and reticulocyte maturity indices during the first year of life in 'large' preterm infants. Eur J Haematol 2007;79:439-46.

34. Van den Bruel A, Thompson MJ, Haj-Hassan T, et al. Diagnostic value of laboratory tests in identifying serious infections in febrile children: systematic review. BMJ 2011;342:d3082. 